\title{
Sunflower biodiesel: efficiency and emissions
}

\author{
J. A. Ali $^{1} \&$ A. Abuhabaya ${ }^{2}$ \\ ${ }^{I}$ School of Chemical and Petroleum Engineering, \\ Koya University, Kurdistan \\ ${ }^{2}$ School of Computing and Engineering, University of Huddersfield, UK
}

\begin{abstract}
With economic development, energy needs have grown, utilizing natural resources such as wood, fossil fuels, and nuclear energy in the last century. However, rising concerns on energy security and climate change in recent years have focused attention on using alternative sources of energy such as bio-fuels. Bio-fuels are produced from renewable resources, particularly plant derived materials, and their production provides alternative nonfossil fuels without the need to redesign current engine technology. This study presents an experimental investigation into the effects of using biodiesel blends on diesel engine performance and its emissions. The biodiesel fuels were produced from sunflower oil using the transesterification process with low molecular weight alcohols and sodium hydroxide then tested on a steady state engine test rig using a four cylinder compression ignition (CI) engine. The paper also shows that blending biodiesel with diesel fuel can reduce harmful gas emissions while maintaining similar performance output and efficiency. Production optimization was achieved by changing the variables which included methanol/oil molar ratio, $\mathrm{NaOH}$ catalyst concentration, reaction time, reaction temperature, and rate of mixing to maximize biodiesel yield. In addition, a second-order model was developed to predict the biodiesel yield if the production criteria is known. It was determined that the catalyst concentration and molar ratio of methanol to sunflower oil were the most influential variables affecting percentage conversion to fuel.
\end{abstract}

Keywords: biodiesel, transesterification, optimization, sunflower oil, engine performance and emission. 


\section{Introduction}

Energy is very important for humans as it is used to sustain and improve their well-being. It exists in various forms, from many different sources. The concerns on global warming and energy security have raised the issue of using alternative sources of energy such as bio-fuels produced from renewable resources such as plant. There are mainly two types of bio-fuels (first generation bio-fuels): ethanol - produced by fermentation of starch or sugar (e.g., grains, sugarcane, sugar-beet, etc.) and biodiesel - produced by processing vegetable oils (e.g., sunflower, rapeseed, palm oil, etc.). Another type of bio-fuel is cellulosic ethanol known as second generation bio-fuel, is produced mainly from wood, grasses and other lignocellulosic materials from renewable sources. Bio-fuels have become a high priority in the European Union, Brazil, the United States and many other countries, due to concerns about oil dependence and interest in reducing greenhouse gas emissions. The European Union Bio-fuels Directive required that member states realize a $10 \%$ share of biofuels (on energy basis) in the liquid fuels market by 2020 [1]. For biodiesel production, most of the European countries use rapeseed and sunflower oil as their main feedstock, soybean oil is the main feedstock in the United States. Palm oil in South-east Asia (Malaysia and Indonesia) and coconut oil in the Philippines are being considered. In addition, some species of plants yielding non-edible oils, e.g. jatropha, karanji and pongamia may play a significant role in providing resources. Biodiesel is derived from vegetable oils or animal fats through transesterification [2] which uses alcohols in the presence of a catalyst that chemically breaks the molecules of triglycerides into alkyl esters as biodiesel fuels with glycerol as a by-product. The commonly used alcohols for the transesterification include methanol and ethanol. Methanol adopted most frequently, due to its low cost. Engine performance testing of biodiesels and their blends is indispensible for evaluating their relevant properties. Several research groups have investigated the properties of a biodiesel blend with soybean oil methyl esters in diesel engines and found that $\mathrm{CO}$ and soot mass emissions decreased, while NOx increased. Labeckas and Slavinskas [3] examined the performance and exhaust emissions of rapeseed oil methyl esters in direct injection diesel engines, and found that there were lower emissions of $\mathrm{CO}, \mathrm{CO}_{2}$ and HC. Similar results were reported by Kalligeros et al. [4] for methyl esters of sunflower oil and olive oil when they were blended with marine diesel and tested in a stationary diesel engine. Raheman and Phadatare [5] studied the fuel properties of karanja methyl esters blended with diesel from $20 \%$ to $80 \%$ by volume. It was found that B20 (a blend of $20 \%$ biodiesel and $80 \%$ petroleum diesel) and B40 could be used as an appropriate alternative fuel to petroleum diesels because they apparently produced less $\mathrm{CO}$, NOx emissions, and smoke density. A technique to produce biodiesel from crude Jatropha curcas seed oil (CJCO) having high free fatty acids (15\% FFA) has been developed by [6], a two-stage transesterification process was selected to improve the methyl ester yield. Lin et al. [7] confirmed that emission of polycyclic aromatic hydrocarbons (PAH) decreased when the ratio of palm biodiesel increased in a blend with 
petroleum diesel. In general, biodiesel demonstrated improved emissions by reducing $\mathrm{CO}, \mathrm{CO}_{2}, \mathrm{HC}$ and $\mathrm{PAH}$ emissions though, in some cases, $\mathrm{NOx}$ increased. The objective of this study was to optimize the production of biodiesel from sunflower oil within a laboratory environment and to evaluate its effectiveness through testing using a laboratory engine test rig. The results showed improved engine performance and reduced exhaust gas emissions with levels acceptable to the standard ASTM D6751 (which was correlated to the content of pigments such as gossypol) [8]. A literature search indicated that little research has been conducted using RSM to analysis the optimal production of biodiesel using vegetable oils. This study intended to make use of the RMS process to maximize the production of biodiesel from sunflower oil using the conventional transesterification method. In addition to using the RMS for optimizing the methanolysis of sunflower oil it was a desire to develop a mathematical model which would describe the relationships between the variables and so allow yield to be predicted before the production process was finalised.

\section{Materials and methods}

\subsection{Materials}

The materials used in this study including methanol, sodium hydroxide and sunflower oil were purchased from Fisher Scientific and local shops in the city of Huddersfield, United Kingdom. The biodiesel from sunflower oil was blended at B5 (5\% of biodiesel to $95 \%$ of standard diesel by volume), B10, B15 and B20 and evaluated for engine performance and exhaust gas emissions compared to standard diesel.

\subsection{Equipment}

Experiments were conducted in a laboratory-scale setup. A $500 \mathrm{ml}$, three-necked flask equipped with a condenser, a magnetic stirrer and a thermometer was used for the reaction. The flask was kept in the $35^{\circ} \mathrm{C}$ water bath and stirring speed was maintained at $200 \mathrm{rpm}$. The reaction production was allowed to settle before removing the glycerol layer from the bottom, and using a separating funnel to obtain the ester layer on the top, separated as biodiesel.

\subsection{Fatty acid profile}

In accordance with the approved method of the American Oil Chemists Society (AOCS), eqn (1) was used to calculate the FFA content of vegetable oils:

$$
\% \text { Free Fatty Acid (as olieic acid) } F F A=\frac{T v \times M \times 28.2}{W}
$$

where $T v$ is titration value $(\mathrm{ml}$ of $\mathrm{NaOH}), \mathrm{M}$ is molarity of $\mathrm{NaOH}(0.025 \mathrm{M})$, and $\mathrm{W}$ is mass of oil sample $(\mathrm{g})$. 


\section{Experimental setup}

\subsection{Biodiesel production process}

The presence of $\mathrm{NaOH}$ is to produce methyl esters of fatty acids (biodiesel) and glycerol as shown in fig. 1. In this study, the reaction temperature was kept constant, at $35^{\circ} \mathrm{C}$. The amount of methanol needed was determined by the methanol/oil molar ratio. An appropriate amount of catalyst dissolved in the methanol was added to the precisely prepared sunflower oil. The percentage of the biodiesel yield was determined by comparing the weight of up layer biodiesel with the weight of sunflower oil added. Fig. 1 shows the reaction conversion of vegetable oils to biodiesel.

Major process: triglyceride to methyl esters

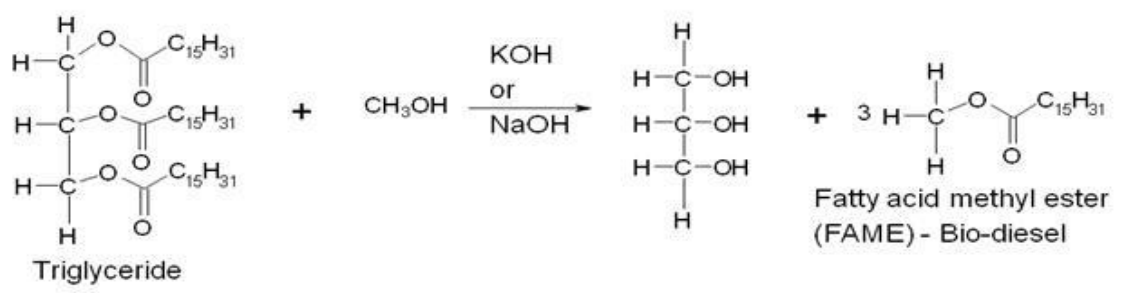

$\mathrm{KOH}+$ Free Fatty Acids = Soap

Figure 1: Chemical reaction for sunflower biodiesel production.

\subsection{Engine test setup}

The performance of the biodiesel produced by the transesterification process was evaluated on a Euro 4 diesel engine mounted on a steady state engine test bed. The engine was a four-stroke, direct injection diesel engine, turbocharged diesel, 2009 2.2L Ford Puma Engine as used on the range of Ford Transit vans. The general specification was bore $=89.9 \mathrm{~mm}$, stroke $=94.6 \mathrm{~mm}$, engine capacity $=$ $2402 \mathrm{cc}$, compression ratio $=17.5: 1$, fuel injection release pressure $=135$ bar, $\max$ power=130 kW@3500 rpm, max torque=375.0 Nm@2000-2250. Emissions were measured using a Horiba EXSA 1500 system, measuring $\mathrm{CO}_{2}$, $\mathrm{CO}, \mathrm{NOx}$ and THC. The test procedure was to run the engine at 25, 50, 75 and $100 \%$ engine load over a range of predetermined speeds, 1500, 2200, 2600, 3000 and $3300 \mathrm{rpm}$. At each of these settings the torque, fuel consumption and emissions were measured, the standard diesel forming the benchmark.

\subsection{Trials and optimization}

Optimization of the transesterification process was conducted via a 3-factor experiment to examine effects of methanol/oil molar ratio $(M)$, reaction time $(T)$, and catalyst concentration $(C)$ on yield of methyl ester using a central composite 
rotatable design (CCRD). The CCRD consisted of 20 experimental runs $(2 k+2 k$ $+m$, where $k$ is the number of factors and $m$ the number of replicated centre points), eight factorial points $(2 k)$, six axial points $(2 \times k)$, and six replicated centre points $(m=6)$. Here $k$ is the number of independent variables, and $k=3$ should provide sufficient information to allow a full second-order polynomial model. The axial point would have $\alpha=1.68$. Results from previous research [9] were used to establish a centre point of the CCRD for each factor. The centre point is the median of the range of values used: $6 / 1$ for methanol/oil molar ratio, $1 \%$ catalyst concentration and $60 \mathrm{~min}$ reaction time. To avoid bias, the 20 experimental runs were performed in random order. Design-Expert 8.0 software was used for regression and graphical analyses of the data obtained. The experimental data was analyzed using response surface regression (RSREG) procedure in the statistic analysis system (SAS) that fits a full second-order polynomial model, eqn (2). The RSREG procedure uses canonical analysis to estimate stationary values for each factor. Using the fitted model, response surface contour plots were constructed for each pair of factors being studied while holding the third factor constant at its estimated stationary point. Confirmatory experiments were carried out to validate the model using combinations of independent variables that were not a part of the original experimental design but within the experimental region.

$$
y=\beta_{0}+\sum_{i=1}^{3} \beta_{i} x_{i}+\sum_{i=1}^{3} \beta_{i i} x_{i}^{2}+\sum_{i=1}^{3} \sum_{j=1}^{2} \beta_{i j} x_{i} x_{j}
$$

where $y$ is $\%$ methyl ester yield, $x_{i}$ and $x_{j}$ are the independent study factors, and $\beta_{0}, \beta_{i}, \beta_{i i}$ and $\beta_{i j}$ are intercept, linear, quadratic, and interaction constant coefficients, respectively. A confidence level of $\alpha=5 \%$ was used to examine the statistical significance of the fitted polynomial model.

\section{Results and discussion}

\subsection{Fatty acid content analysis}

Since higher amounts of free fatty acid (FFA) $(>1 \% \mathrm{w} / \mathrm{w})$ in the feedstock can directly react with the alkaline catalyst to form soaps, which can then form stable emulsions and prevent separation of the biodiesel from the glycerol fraction and decrease the yield, it is better to select reactant oils with low FFA content or to reduce FFA in the oil to an acceptable level before the reaction. Nevertheless, the FFA (calculated as oleic acid) content of the sunflower oil used in this experiment was, on average, only $0.13 \%$ which was within acceptable levels to be directly used for reaction with the alkaline catalyst to produce biodiesel [10]. The remaining main factors affecting the transesterification include reaction time, temperature, molar ratio, rate of mixing, and catalyst concentration.

\subsection{Modelling the biodiesel production}

The regression coefficients for the second-order polynomial model, eqn (3) show that the linear terms for methanol/oil molar ratio and catalyst concentration $(M$ 
and $C$, respectively), the quadratic terms in $M^{2}$ and $C^{2}$, and the interaction terms in $T C$ and $T M$ had significant effects on the yield. Among these, $M, C, C^{2}$ and $M C$ were significant at the significance level, while $M^{2}$ and $T M$ were significant at the level. Using these coefficients which have been determined from DesignExpert 8.0 software program, the predicted model in terms of uncoded factors for methyl ester yield is:

$$
\begin{gathered}
Y_{\text {yield }}=-121.52-1.29 T+32.05 M+183.66 C+0.49 T M-0.59 T C \\
-4.44 M C-0.05 T^{2}-1.99 M^{2}-62.91 C^{2}
\end{gathered}
$$

where $\mathrm{Y}$ is the methyl ester yield, and $T, M$ and $C$ are the actual values of the test variables. The results suggest that linear effects of changes in molar ratio (M) and catalyst concentration (C) and the quadratic effect $\mathrm{C}^{2}$ were primary determining factors on the methyl ester yield as these had the largest coefficients. That the quadratic effect, $\mathrm{M}^{2}$ and the interaction effect $\mathrm{MC}$ were secondary determining factors and those other terms of the model showed no significant effect on yield. Positive coefficients, as with $\mathrm{M}$ and $\mathrm{C}$, enhance the yield. However, all the other terms had negative coefficients. Fig. 2 show the predicted yield obtained by eqn (3) denoted by solid line and comparison with experimental measured yield for twenty runs.

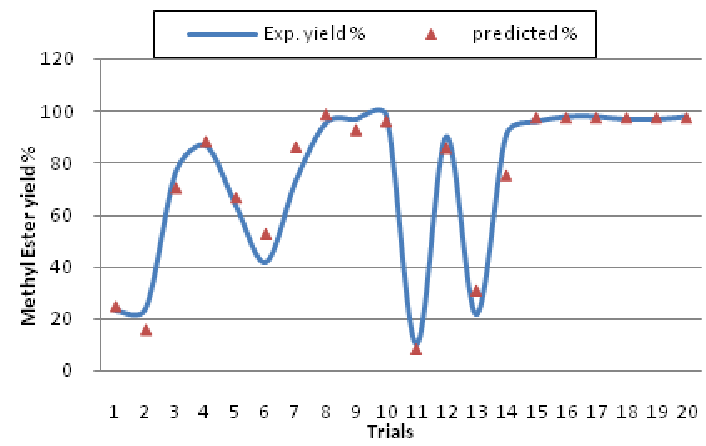

Figure 2: Biodiesel production predicted data and comparison with experimental measured data.

\subsection{Engine performance and emission results}

\subsubsection{Brake performance analysis}

Due to the fact that the lower calorific value of biodiesel, both torque and brake power reduces. Figs. 3 and 4 show the effect of standard diesel and biodiesel fuel on brake power and torque respectively. However, the differences between standard diesel and biodiesel were very small in most cases. Fig. 5 presents the effects of standard diesel and biodiesel fuel on BSFC; a bigger difference is shown in a higher speed engine. The increase of BSFC may be attributed to the higher density, higher fuel consumption and lower brake power due to lower calorific value of the biodiesel. 


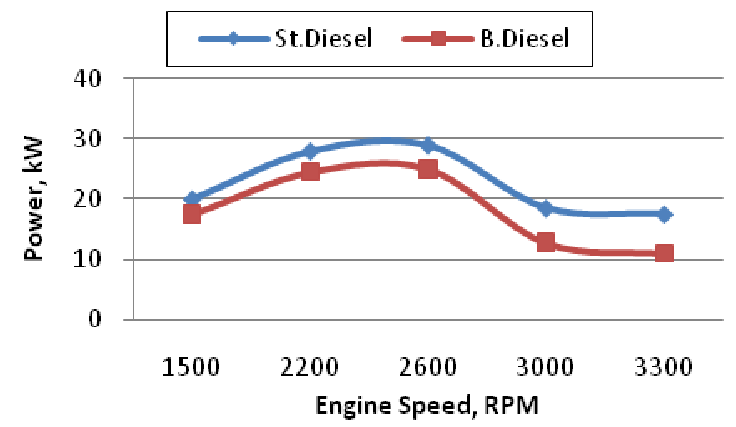

Figure 3: Variation of the brake power with the engine speed, at full load.

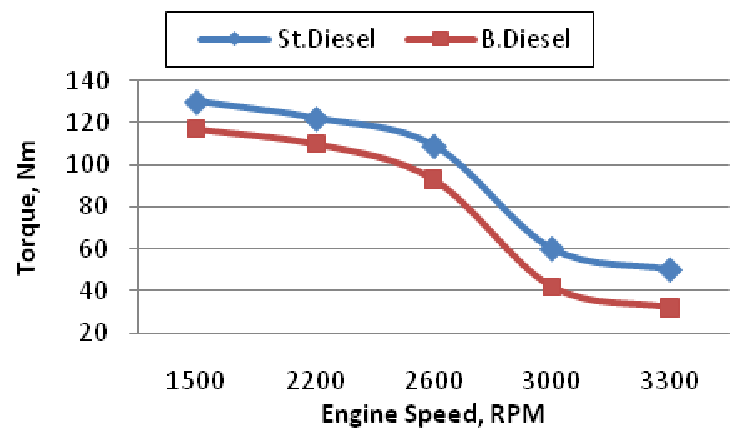

Figure 4: Variation of the brake torque with the engine speed, at full load.

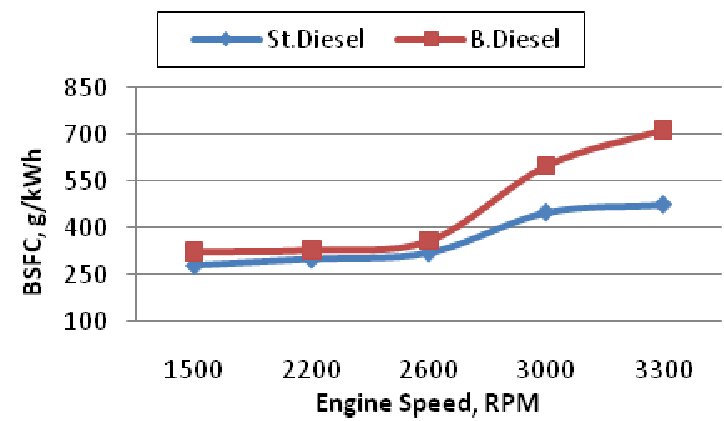

Figure 5: Variation of BSFC with the engine speed, at full load.

\subsubsection{Engine performance analysis}

Sunflower oil itself has relatively low energy content, but the biodiesel fuel produced from it has a value (about $37.5 \mathrm{MJ} / \mathrm{kg}$, close to that of petroleum diesel; this means that efficiency and output is lower but only by a small percentage. Figs. 6 and 7 show the curves for engine power and torque respectively. By simple proportions the energy content of the blend can be calculated. Energy content of blend $=(\%$ diesel x $42.5+\%$ biodiesel x 37.5$)$. It 


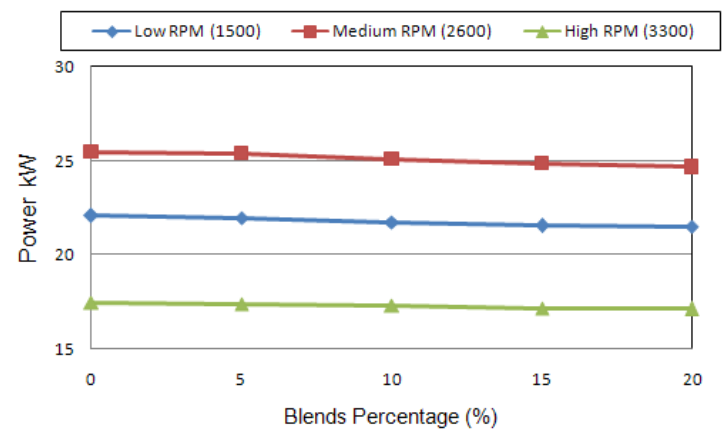

Figure 6: Average power output for different biodiesel blends.

can be seen from fig. 6 that the loss in power is close to the value predicted. At $20 \%$ biodiesel the calculated power is $41.5 \mathrm{MJ} / \mathrm{kg}$, a decrease of $2.35 \%$ compared to petroleum diesel, the measured decrease was about $1.72 \%$.

The same trend in the results was seen for torque, there was a progressive decrease in torque as the proportion of biodiesel in the blend increased (see figs. 6 and 7). The decrease in torque was more apparent than that of the power, because diesel engines are more focused on torque curves than power curves.

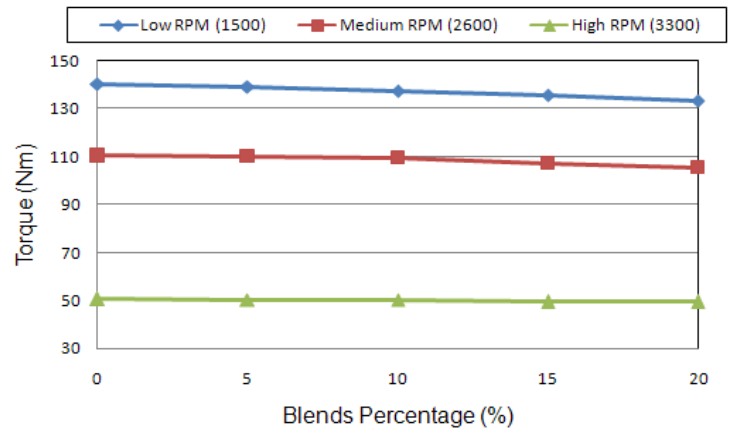

Figure 7: $\quad$ Torque output for different biodiesel blends.

\subsubsection{Engine exhaust gas emissions analysis}

As was stated previously the results of biodiesel blend fuels over the petroleum diesel should show decrease in the emissions of $\mathrm{CO}, \mathrm{HC}$, with a slight increase in NOx, and overall similar values for $\mathrm{CO}_{2}$. This trend can be seen in fig. 8 .

When biodiesel is present there is additional carbon, hydrogen and oxygen to be added to the reaction. The resulting problem is seen at $\mathrm{B} 5$, this additional carbon caused the emitted $\mathrm{CO}_{2} \%$ to increase. This then falls as the proportion of biodiesel is increased and a state similar to that for diesel fuel is reached at about B20. Following this trend it is estimated that at higher concentrations of biodiesel blends ( $>$ B20) the $\mathrm{CO}_{2} \%$ emitted would actually be lower than for diesel fuel. 


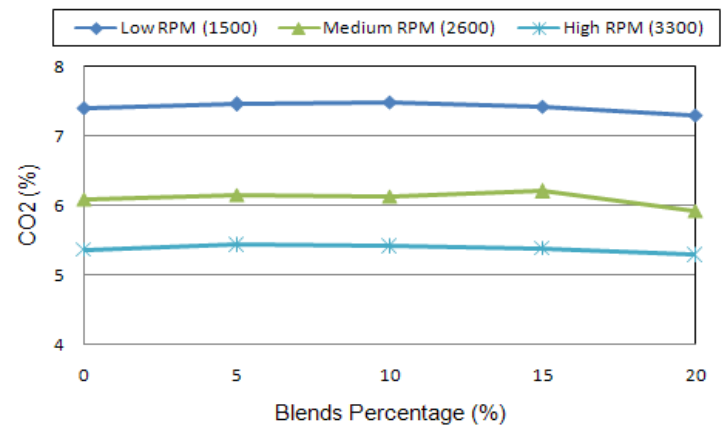

Figure 8: Variation of carbon dioxide emissions for different biodiesel.

The second emission to be analyzed is CO. Carbon Monoxide is present when dissociation is present in the combustion due to incomplete combustion. Fig. 9 shows the $\mathrm{CO}$ emission for the biodiesel obtained from sunflower oil. From the data it was clear that the $\mathrm{CO}$ emission decreased as the biodiesel blend increased.

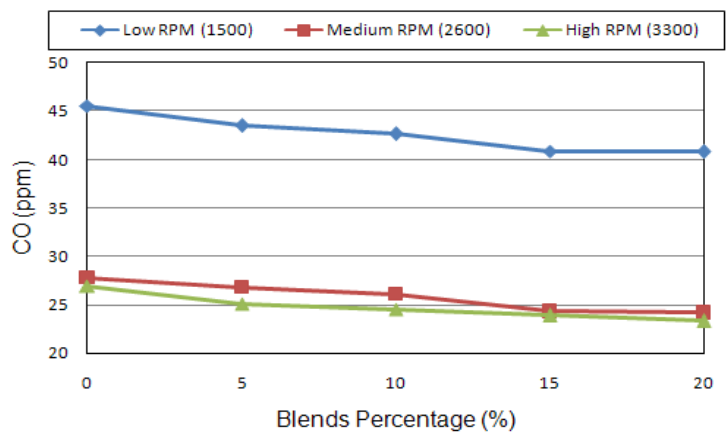

Figure 9: Variation of carbon monoxide emissions for different biodiesel blends.

Hydrocarbon emission should be reduced by the use of biodiesel. From the data in fig. 10 was significant and substantial decrease in $\mathrm{HC}$ emissions. As the combustion becomes more complete less dissociation occurs yielding fewer hydrocarbons in the emissions. The decrease in HCs from over $40 \mathrm{ppm}$ to less than $30 \mathrm{ppm}$ is good for a fuel which is as efficient as diesel fuel but friendlier to the environment. An oxide of nitrogen (NOx) was the only emission which did not seem to show a decrease relative to diesel fuel. In fact it increasing steadily as the percentage of biodiesel blend increased (see fig. 11). From the data it was apparent that the change is only being incremented at $\mathrm{B} 20$ by a maximum value of $3.21 \%$, yet with a mean more resembling that of $2.33 \%$. An oxide of nitrogen is the only emission which did not seem to show a decrease relative to petroleum diesel. In fact it increasing steadily as the percentage of biodiesel blend increased. 


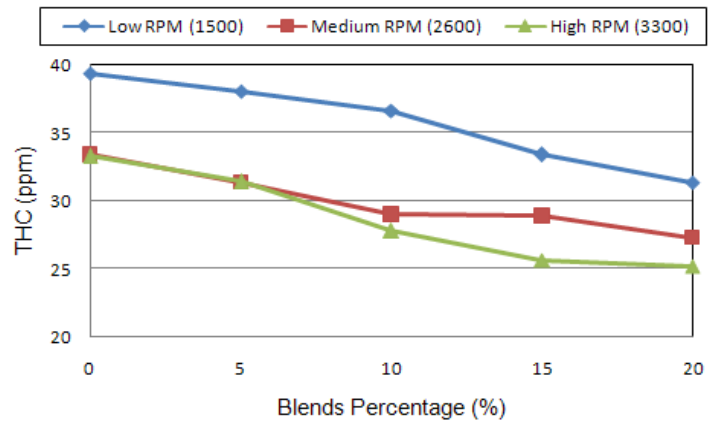

Figure 10: Variation of hydrocarbon emissions for different biodiesel blends.

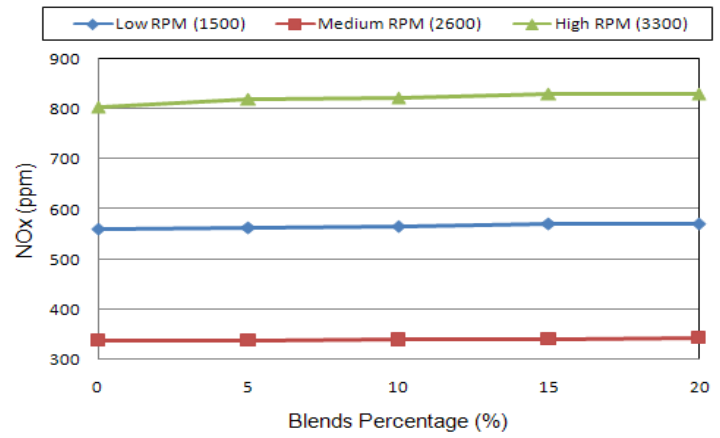

Figure 11: Variation of oxide of nitrogen emissions for different biodiesel blends.

In addition to sunflower biodiesel, various vegetable oils tested in this study to compare the engine exhaust emissions. Fig. 12 shows the effects of standard diesel and biodiesel fuel on (HC) emission, Biodiesel produces lower HC emission. This may be attributed to the availability of oxygen in biodiesel, which facilitates better combustion. Also, $\mathrm{HC}$ emission of biodiesel was almost

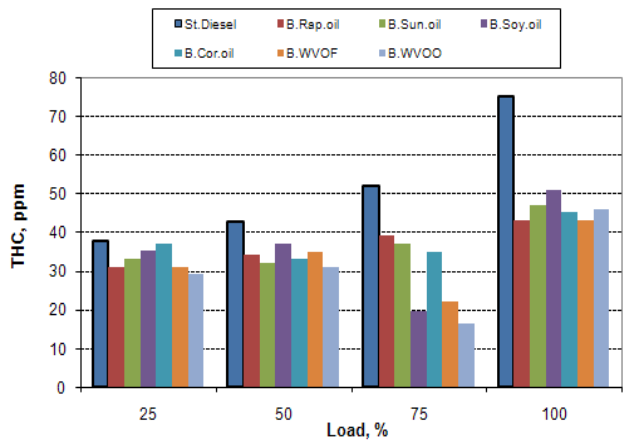

Figure 12: Variation of hydrocarbon emissions with load for fuels tested. 


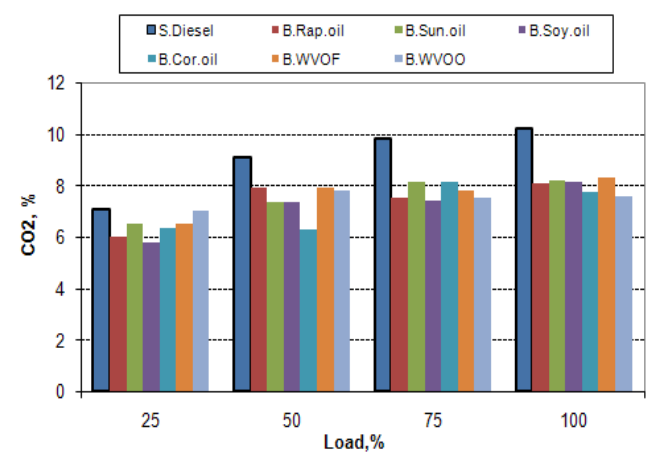

Figure 13: Variation of carbon dioxide emissions with load for fuels tested.

identical. Fig. 13 shows the effects of the other biodiesel on $\mathrm{CO}_{2}$ emission and comparison with the standard diesel effect.

\section{Conclusion}

The study showed that after testerification of vegetable oils, the kinematic viscosity is reduced from $40 \mathrm{~mm}^{2} / \mathrm{s}$ to $5 \mathrm{~mm}^{2} / \mathrm{s}$. For the analyzed samples, the properties were similar in some cases and different in others. Any types of vegetable oils biodiesel can be used as an alternate and nonconventional fuel to run all types of $\mathrm{CI}$ engine. By running biodiesel fuel, the experiential data was showed decreased in almost all the emissions $\left(\mathrm{CO}\right.$, THC and $\left.\mathrm{CO}_{2}\right)$ except for NOx. The study has shown that no matter what type of feedstock is used there will be very similar decreases in emissions and performance of the engine. From the combustion analysis it was found the performance of the B20 was as good as that of standard diesel and the difference in the brake power and torque were very small in most cases. RSM proved to be a powerful tool for the optimization of methyl ester production at a fixed temperature. The optimal conditions for the maximum methyl ester yield were found to be at methanol/oil molar ratio of $7.7: 1, \mathrm{NaOH}$ catalyst concentration of $1 \%$, reaction temperature $35^{\circ} \mathrm{C}$, rate of mixing $200 \mathrm{rpm}$ and a reaction time of $60 \mathrm{~min}$.

\section{References}

[1] European Commission, "Impact Assessment of the Renewable Energy Roadmap - March 2007, Directorate-General for Agriculture and Rural Development, European Commission”, AGRI, G2/WMD, 2007, Available at: http://ec.europa.eu/agriculture/analysis/markets/biofuel/ impact042007/text_en.pdf

[2] Abuhabaya, A., Fieldhouse, J. and Brown, R. "Evaluation of properties and use of waste vegetable oil (WVO), pure vegetable oils and standard diesel as used in a compression ignition engine," Computing and Engineering University of Huddersfield, Huddersfield, UK, pp. 71-76, 2010 . 
[3] Labeckas, G. and Slavinskas, S. "The Effect of Rapeseed Oil Methyl Ester on Direct Injection Diesel Engine Performance and Exhaust Emissions,” Energy Convers Manage, vol. 47, pp. 1954-1967, 2006.

[4] Kalligeros, S., Zannikos, F., Stournas, S., Lois, E., Anastopoulos, G., Teas, Ch. and Sakellaropoulos, F. "An Investigation of Using Biodiesel/Marine Diesel Blends on the Performance of a Stationary Diesel Engine," Biomass Bioenerg vol. 24, pp. 141-149, 2003.

[5] Raheman, H. and Phadatare, A. G. "Diesel Engine Emissions and Performance from Blends of Karanja Methyl Ester and Diesel," Biomass Bioenerg, vol. 27, pp. 393-397, 2004.

[6] Berchmans, H. J. and Hirata, S. "Biodiesel production from crude Jatropha curcas L. seed oil with a high content of free fatty acids" Bioresource Technology, vol. 99, pp. 1716-1721, 2008.

[7] Lin, Y. C., Lee, W. J. and Hou, H. C. "PAH Emissions and Energy Efficiency of Palm-Biodiesel Blends Fueled on Diesel Generator," Atmos Environ, vol. 40, pp. 3930-3940, 2006.

[8] Ahmad, M., Ahmed, S., Ul-Hassan, F., Arashad, M., Khan, M., Zafar, M. and Sultana, S. "Base catalyzed transesterification of sunflower oil Biodiesel" African Journal of Biotechnology, vol. 9, pp. 8630-8635, 2010.

[9] Yuan, X. Z., Liu, J., Zeng, G. M, Shi, J. G., Tong, J. Y. and Huang, G. H. "Optimization of conversion of waste rapeseed oil with high FFA to biodiesel using response surface methodology," Renew Energ, vol. 33, pp. 1678-1684, 2008.

[10] Gerpen, J. V. "Bio-diesel processing and production," Fuel Process Technol, vol. 86, pp. 1097-1107, 2005. 